\title{
1 Construction, validation and application of nocturnal pollen \\ 2 transport networks in an agro-ecosystem: a comparison using \\ 3 microscopy and DNA metabarcoding
}

4 Running title: Constructing nocturnal pollination networks

$5 \quad$ Word count: 4676

6

7 Callum J. Macgregor ${ }^{1,2,3,4,5}$, James J.N. Kitson ${ }^{1,2}$, Richard Fox ${ }^{3}$, Christoph Hahn ${ }^{2,6}$, David H.

8 Lunt $^{2}$, Michael J.O. Pocock ${ }^{4}$, and Darren M. Evans ${ }^{1}$

$9{ }^{1}$ School of Natural and Environmental Sciences, Newcastle University, Newcastle upon

10 Tyne, NE1 7RU, UK.

$11{ }^{2}$ School of Environmental Sciences, University of Hull, Cottingham Road, Hull, HU6 7RX, 12 UK.

$13{ }^{3}$ Butterfly Conservation, Manor Yard, East Lulworth, Wareham, Dorset, BH20 5QP, UK.

$14{ }^{4}$ Centre for Ecology and Hydrology, Maclean Building, Benson Lane, Crowmarsh Gifford,

15 Wallingford, Oxfordshire, OX10 8BB, UK.

$16{ }^{5}$ Department of Biology, University of York, Wentworth Way, York, YO10 5DD, UK.

$17{ }^{6}$ Institute of Zoology, University of Graz, A-8010 Graz, Austria.

19 Corresponding author:

20 Callum J. Macgregor

21 Email: callumjmacgregor@gmail.com

22 Tel: (+44) 01904328632

23 Current address: Department of Biology, University of York, Wentworth Way, York, YO10 24 5DD, UK. 


\section{Abstract}

\section{Keywords}

58 ecological networks, flowers, Lepidoptera, light microscopy, moths, pollen transport

1. Moths are globally relevant as pollinators but nocturnal pollination remains poorly understood. Plant-pollinator interaction networks are traditionally constructed using either flower-visitor observations or pollen-transport detection using microscopy. Recent studies have shown the potential of DNA metabarcoding for detecting and identifying pollen-transport interactions. However, no study has directly compared the realised observations of pollen-transport networks between DNA metabarcoding and conventional light microscopy.

2. Using matched samples of nocturnal moths, we construct pollen-transport networks using two methods: light microscopy and DNA metabarcoding. Focussing on the feeding mouthparts of moths, we develop and provide reproducible methods for merging DNA metabarcoding and ecological network analysis to better understand species-interactions.

3. DNA metabarcoding detected pollen on more individual moths, and detected multiple pollen types on more individuals than microscopy, but the average number of pollen types per individual was unchanged. However, after aggregating individuals of each species, metabarcoding detected more interactions per moth species. Pollentransport network metrics differed between methods, because of variation in the ability of each to detect multiple pollen types per moth and to separate morphologically-similar or related pollen. We detected unexpected but plausible moth-plant interactions with metabarcoding, revealing new detail about nocturnal pollination systems.

4. The nocturnal pollination networks observed using metabarcoding and microscopy were similar, yet distinct, with implications for network ecologists. Comparisons between networks constructed using metabarcoding and traditional methods should therefore be treated with caution. Nevertheless, the potential applications of metabarcoding for studying plant-pollinator interaction networks are encouraging, especially when investigating understudied pollinators such as moths. 
bioRxiv preprint doi: https://doi.org/10.1101/325084; this version posted May 17, 2018. The copyright holder for this preprint (which was not certified by peer review) is the author/funder, who has granted bioRxiv a license to display the preprint in perpetuity. It is made available under aCC-BY-NC-ND 4.0 International license.

59

60 


\section{Introduction}

62 Species interaction networks, which describe the presence and strength of interspecific

63 interactions within ecosystems (Montoya et al., 2006), are an important tool in understanding

64 and conserving ecosystem processes and functioning (Tylianakis et al., 2010). Currently,

65 there is considerable interest in pollination networks, due to ongoing global declines in

66 pollinating insects (Potts et al., 2010) and their role in reproduction of both wild plants and

67 crops (Klein et al., 2007; Ollerton et al., 2011).

68 Many flower-visiting animals are not effective pollinators, and proving the existence of an

69 effective pollination interaction is labour-intensive (King et al., 2013). Consequently, proxies

70 for pollination are often used to construct plant-pollinator interaction networks, which cannot

71 strictly be referred to as pollination networks. A commonly-used proxy is flower-visitation,

72 recorded by directly observing animals visiting flowers. This is effective for daytime

73 sampling, but is challenging to apply to nocturnal pollinators, such as moths (Lepidoptera;

74 Macgregor et al., 2015), because observations are difficult and may be biased if assisted by

75 artificial light. This may explain why plant-pollinator network studies frequently omit nocturnal

76 moths, even though moths are globally relevant pollinators (Macgregor et al., 2015).

77 An alternative to direct observation is detecting pollen transport, by sampling and identifying

78 pollen on the bodies of flower-visiting animals; this approach has been used in several

79 previous studies of nocturnal pollination by moths (Devoto et al., 2011; Banza et al., 2015;

80 Knop et al., 2017; Macgregor et al., 2017a). By analysing pollen transport, flower-visits

81 where no pollen is received from the anthers are excluded (Pornon et al., 2016). This

82 approach can detect more plant-pollinator interactions with lower sampling effort than flower-

83 visitor observations (Bosch et al., 2009). Studies of pollen transport also permit unbiased

84 community-level sampling of interactions without requiring decisions about distribution of

85 sampling effort among flower species, as each pollinator carries a record of its flower-visiting

86 activities in the pollen on its body (Bosch et al., 2009). Traditionally, pollen identification is

87 undertaken using light microscopy with a reference collection of known species (e.g. Devoto

88 et al., 2011). However, identifications made by microscopy can be ambiguous, especially

89 when distinguishing related species (Galimberti et al., 2014). Accurate, reproducible

90 identification of pollen sampled from pollinators is necessary to ensure plant-pollinator

91 networks are free from observer bias.

92 A recent alternative to microscopy is DNA metabarcoding: high-throughput sequencing of

93 standard reference loci from communities of pooled individuals (Cristescu, 2014). It offers

94 possibilities to detect interspecific interactions, including plant-pollinator interactions (Evans 
95

96

97

98

99

100

101

102

103

104

105

106

107

108

109

110

111

112

113

114

115

116

117

118

119

120

121

122

123

124

125

126

127

128

129

130

et al., 2016), and methods are rapidly improving, permitting greater accuracy in species identification (Bell et al., 2016a) for reducing costs (Kamenova et al., 2017). Studies using metabarcoding have identified pollen sampled from honey (Hawkins et al., 2015; de Vere et al., 2017) and directly from bees (Galimberti et al., 2014) and flies (Galliot et al., 2017), and constructed plant-pollinator networks (Bell et al., 2017; Pornon et al., 2017). DNA sequences have confirmed identities of single pollen grains sampled from moths (Chang et al., 2018), but no study has applied metabarcoding to nocturnal pollen-transport by moths, where pollen-transport approaches may be most valuable, given the paucity of existing knowledge about moth-plant pollination interactions. Metabarcoding reveals more plant-pollinator interactions than direct flower-visitor observations (Pornon et al., 2016, 2017), but it is unclear whether this is purely because pollen-transport approaches detect interactions more efficiently than flower-visitation approaches (Bosch et al., 2009) or whether metabarcoding offers specific additional benefits. Use of a metabarcoding approach is often justified by the labour-intensive nature of microscopy-based approaches and the level of expertise required to identify pollen morphologically (e.g. de Vere et al., 2017). It is frequently suggested that metabarcoding increases the level of species discrimination compared to traditional approaches (Bell et al., 2017). Crucially, despite this assertion, no study has directly compared metabarcoding to traditional microscopy for assessing pollen transport. It is therefore unknown whether, in studies using a pollen-transport approach, the choice of detection method (light microscopy or DNA metabarcoding) can alter the realised observations of plant-pollinator interactions.

In this study, we used matched samples of moths to construct nocturnal pollination networks using two methods: DNA metabarcoding, and the traditional light microscopy approach; and compared the observed networks, considering the quantity and nature of the interactions detected and the properties of the networks themselves. We sampled moths in a UK agroecosystem, as our previous study suggests that moths may have greater importance as pollinators in such systems than generally thought (Macgregor et al., 2017a). Accordingly, we developed existing pollen-metabarcoding protocols to enable detection of pollen transported by moths, and integrated molecular advances with ecological network analysis to provide a reproducible methodology for the improved study of species-interactions. By providing detailed descriptions of our methods (dx.doi.org/10.17504/protocols.io.mygc7tw, Appendix S1) and archiving all bioinformatic and statistical code (dx.doi.org/10.5281/zenodo.1169319), we present a framework for future studies of pollination networks using metabarcoding. We discuss the advantages and disadvantages of each method for assessment of pollen transport by moths and other pollinator taxa, current limitations and future research directions. 


\section{Materials and methods}

\section{Field sampling}

133 We sampled moths, using light-traps, from four locations in a single farmland site in the East

134 Riding of Yorkshire, UK (5351'44" N $0^{\circ} 25^{\prime} 14$ " W), over eight nights between 30th June and

135 19th September 2015 (Table S1; full details in Appendix S1). Moths were euthanised and

136 retained individually. As both pollen-sampling methods are destructive, it was impossible to

137 directly compare sensitivity by sampling pollen from the same individual moth with both

138 methods. Instead, we created two matched sub-samples of moths, each containing the

139 same set of species, and the same number of individuals of each. Pollen-transport by each

140 sub-sample was analysed using one method (Fig. 1). With both methods, we restricted

141 pollen sampling to the proboscis, because most moth species coil their proboscides unless

142 actively feeding (Krenn, 1990). Therefore, the proboscis is unlikely to experience cross-

143 contamination of pollen through contact with other moths (e.g. whilst in the moth-trap), and

144 pollen held on the proboscis is probably the result of a flower-visitation interaction.

\section{Method 1: light microscopy}

146 A standard approach for pollen sampling was applied (Beattie, 1972), in which $1 \mathrm{~mm}^{3}$ cubes

147 of fuchsin jelly were used to swab pollen from the proboscides of moths, and the pollen

148 examined under a light microscope at 400x magnification. Pollen morphotypes were

149 identified using a combination of keys (Moore et al., 1994; Kapp et al., 2000) and knowledge

150 of likely insect-pollinated plant taxa. Morphotypes (equivalent to operational taxonomic units,

151 OTUs) represented groupings that could not be unambiguously separated to a lower

152 taxonomic level, and might have contained pollen from multiple species.

\section{Method 2: DNA metabarcoding}

154 Protocols for DNA extraction, amplification and sequencing are fully described in Appendix

$155 \mathrm{~S} 1$ and archived online (dx.doi.org/10.17504/protocols.io.mygc7tw). In brief, the protocols

156 were as follows. Moth proboscides were excised using a sterile scalpel. Pollen was removed

157 from each proboscis by shaking for 10 minutes in HotSHOT lysis reagent (Truett et al., 2000)

158 at $2000 \mathrm{rpm}$ on a Variomag Teleshake plate shaker (Thermo Scientific, Waltham, MA). The

159 proboscis was removed using sterile forceps, and the DNA extraction procedure completed

160 on the remaining solution following Truett et al. (2000). Extracted DNA was amplified using a

161 three-step PCR nested tagging protocol (modifed from Kitson et al., n.d. in press; see

162 Appendix S1). We amplified a custom fragment of the rbcL region of chloroplast DNA, which

163 has been previously used for metabarcoding pollen (Hawkins et al., 2015; Bell et al., 2017) 
164 and has a comprehensive reference library for the Welsh flora, representing $76 \%$ of the UK

165 flora (de Vere et al., 2012), available on the International Nucleotide Sequence Database

166 Collaboration (http://www.insdc.org/; GenBank). We used two known binding sites for

167 reverse primers, rbcL-19bR (Hofreiter et al., 2000) and rbcLr506 (de Vere et al., 2012), to

168 produce a working forward and reverse universal primer pair, rbcL-3C (rbcL-3CF: 5'-

169 CTGGAGTTCCGCCTGAAGAAG-3'; rbcL-3CR: 5'-AGGGGACGACCATACTTGTTCA-3').

170 Primers were validated by successful amplification of DNA extracts from 23/25 plant species

171 (Table S2). Sequence length varied widely (median: 326 base pairs (bp), range: 96-389 bp);

172 fragments shorter than 256 bp generally had no match on GenBank. Six control samples

173 were used to monitor cross-contamination between wells (Table S3).

174 Amplified DNA was sequenced on an Illumina MiSeq, using V2 chemistry. Taxonomic

175 assignment of MiSeq output was conducted using the metaBEAT pipeline, version 0.97.7

176 (https://github.com/HullUni-bioinformatics/metaBEAT). For reproducibility, all steps were

177 conducted in Jupyter notebooks; all bioinformatic and statistical code used in this study is

178 archived online (dx.doi.org/10.5281/zenodo.1169319) and procedures are explained in full in

179 Appendix S1. Taxonomic assignment of sequences was conducted within metaBEAT based

180 on a BLAST Lowest Common Ancestor approach implemented in MEGAN (Huson et al.,

181 2007). We chose to conduct taxonomic assignment with BLAST because it is among the

182 most widely-used taxonomic assignment tools, and blastn specifically has a proven capacity

183 to discriminate between UK plant species using the rbcL locus (de Vere et al., 2012). We

184 used a curated database of reference sequences from plausibly-present plant species

185 previously recorded in the vice-county of South-east Yorkshire (reference list of species

186 archived at $\mathrm{dx}$. doi.org/10.5281/zenodo.1169319).

187 To eliminate the risk of cross-well contamination, we established a threshold for minimum

188 read depth of 50 reads, per assignment, per well. The maximum read depth in any negative

189 control well was 47, and the maximum read depth in any positive control well of sample

190 assignments was 33 (Table S3). Therefore, this threshold was adequate to remove sample

191 reads from positive and negative controls. Within each well, any assignment with a read

192 depth below 50 was reset to 0 prior to statistical analysis; this resulted in some plant OTUs

193 being removed entirely from the dataset (however, these OTUs are indicated in Table 1).

194 Curation of data

195 We harmonised the plant identifications from each method (OTUs from metabarcoding and

196 morphotypes from microscopy) to produce a single list of plants consistent across both

197 methods (Table 1). Specifically, for metabarcoding, we revised family-level assignments 
198 made by BLAST, inspecting the range of species-level matches to identify clear taxonomic

199 clusters within the families. For microscopy, we attempted to re-identify pollen morphotypes

200 using images of pollen from species identified by metabarcoding for additional reference

201 (see Appendix S1). Microscopic photographs of pollen were sourced from two online

202 repositories of pollen images: Pollen-Wiki

203 (http://pollen.tstebler.ch/MediaWiki/index.php?title=Pollenatlas) and the Pollen Image Library

204 (http://www-saps.plantsci.cam.ac.uk/pollen/index.htm).

\section{Comparison of methods and statistical analysis}

206 We tested for differences between the two identification methods, examining whether

207 sampling method affected the likelihood of detecting (i) pollen on individual moths; (ii) more

208 than one pollen species on individuals; (iii) pollen on moth species (individuals combined);

209 and whether sampling method affected the number of pollen types detected (iv) per

210 individual moth; and per moth species, using (v) observed richness and (vi) true richness

211 estimated using the Chao2 estimator (Chao, 1987). We used generalised linear mixed-

212 effects models (GLMMs), with sampling method as a fixed effect. In individual-level

213 analyses, we used date/light-trap combination ('trap ID') as a random effect, whilst in

214 species-level analyses, we used moth species as a random effect to treat the data as pairs

215 of observations (one observation, per method, per moth species). We tested significance of

216 fixed effects using either Likelihood Ratio Tests or Type III ANOVA, depending on error

217 distribution. Analysis was carried out with $\mathrm{R}$ version 3.3.2 (R Core Team, 2016); all code is

218 archived at $\mathrm{dx}$.doi.org/10.5281/zenodo.1169319.

\section{Sampling completeness and networks}

220 For both methods, we estimated sampling completeness of interactions, following Macgregor et al. (2017b). For each method, we estimated the total number of pollen types (interaction richness) for each insect species with the Chao2 estimator (Chao, 1987), using the $R$ package vegan (Oksanen et al., 2015). We calculated interaction sampling completeness for each species as $100^{*}$ (observed interactions)/(estimated interactions) for each species.

225 Finally, we calculated the mean interaction sampling completeness of all species, weighted by estimated interaction richness of each species.

227 We constructed pollen-transport networks from the interaction data. We used presence of 228 interactions between individual moths and plant taxa, rather than strength of individual 229 interactions, because read depth (metabarcoding) and pollen count (microscopy) are not 230 equivalent. We measured interaction frequency by counting interactions across all individuals in each moth species; interaction frequency correlates positively with true 
232 interaction strength in mutualistic networks (Vázquez et al., 2005). We calculated several

233 quantitative metrics, as follows, to describe the diversity and specialisation of interactions

234 forming each network. Improved detection of interactions could increase the complexity of

235 the network, so we calculated two measures of network complexity: linkage density (average

236 no. links per species) and connectance (proportion of possible interactions in the network

237 that are realized). Likewise, improved detection of plant species with the same set of

238 pollinator species could alter consumer-resource asymmetry and perceived specialization of

239 species in the network, so we calculated H2' (a frequency-based index that increases with

240 greater specialization), generality of pollinators, and of plants (average no. links to plant

241 species per pollinator species, and vice versa). Finally, the resilience of the network to

242 cascading species loss may be influenced by its complexity (Dunne et al., 2002), so we

243 measured the robustness of each network (mean robustness across 1000 bootstrapped

244 simulations of pollinator species loss). For comparison, we repeated all network analyses

245 with plant identities aggregated at family-level, because the methods might differ in their

246 ability to distinguish closely-related species. Networks were analysed using the package

247 bipartite (Dormann et al., 2009) and plotted using Food Web Designer 3.0 (Sint \& Traugott,

248 2016). As we could only construct one network for each method, we recorded obvious

249 differences between the metrics for each network but could not statistically assess the

250 significance of those differences.

\section{Results}

\section{Summary}

253 In total, we caught 683 moths of 81 species, generating two matched sub-samples, each

254 containing 311 moths of 41 species (Table S4). We detected pollen on 107 individual moths

255 with metabarcoding (34\% of the sub-sample) and 70 (23\%) with microscopy. We initially

256 identified 20 plant morphotypes in the microscopy sample and 25 OTUs in the

257 metabarcoding sample (Table 1). After harmonising these we recorded 33 plant identities (at

258 varying taxonomic resolution), of which 18 were detected with both methods, 11 with

259 metabarcoding only (including three which failed to meet the minimum read depth threshold

260 in any sample), and four by microscopy only.

\section{Statistical comparisons between methods}

262 Metabarcoding was significantly more likely than microscopy to detect pollen (Fig. 2) on

263 individual moths $\left(\square^{2}=10.95, P<0.001\right)$, and to detect more than one pollen type on

264 individual moths $\left(\square^{2}=12.00, P<0.001\right)$. However, with non-pollen-carrying moths excluded, 265 the methods did not differ in the number of pollen types detected per individual moth $\left(\square^{2}=\right.$ 
$2661.12, P=0.290)$. With data aggregated per moth species, the methods did not differ in the

267 likelihood of detecting pollen $\left(\square^{2}=0.37, P=0.545\right)$, but metabarcoding detected significantly

268 more pollen types per moth species $\left(\square^{2}=18.09, P<0.001\right)$; this difference was non-

269 significant when the estimate of true interaction richness was used $\left(\square^{2}=3.62, P=0.057\right.$;

270 Table S5).

\section{Construction and analysis of networks}

272 For each method, we constructed a quantitative pollen-transport network (Fig. 3). The 273 estimated sampling completeness of interactions was higher for the microscopy network $274(75.7 \%)$ than the metabarcoding network (43.2\%). Some network metrics differed markedly 275 between the two methods (Fig. 4), though no statistical comparison was appropriate.

276 Specifically, linkage density and generality of pollinators were higher in the metabarcoding

277 network than the microscopy network, but all other metrics were similar. With plant

278 assignments aggregated at family level, the metabarcoding network had higher generality of 279 pollinators and lower generality of plants than the microscopy network (Table S6).

\section{Discussion}

\section{Methodological comparison}

282 Our realised observations of the plant-pollinator system were generally similar between the 283 DNA-based (metabarcoding) and microscopy-based methods for detecting and identifying 284 pollen-transport by moths, but nonetheless showed some key differences. Metabarcoding 285 detected more pollen OTUs in total than microscopy, detected pollen on a greater proportion 286 of individual moths, and was more likely to detect multiple pollen OTUs on a moth. When 287 moths were aggregated to species level, metabarcoding detected more pollen types in total 288 per moth species.

289 We observed differences between the networks detected by each method, which can be 290 attributed to metabarcoding detecting more separate species within some plant families, and 291 detecting interactions with more plant families per pollinator species. This is revealed by the 292 higher generality of pollinators in the fully-resolved metabarcoding network than its 293 equivalent microscopy network, and the lesser increase in generality of pollinators, 294 combined with lower generality of plants, in the family-level metabarcoding network than its 295 equivalent (Fig. 4). Additionally, linkage density was higher for metabarcoding than 296 microscopy in the fully-resolved networks, but not in the family-level networks (Fig. 4). 
297 Estimated sampling completeness of interactions differed conspicuously between networks

298 (Table S6). Despite containing more interactions, the metabarcoding network was estimated

299 to be less completely sampled than the microscopy network. This is probably because

300 metabarcoding detected more 'rare' interactions ('singletons', detected only once), being

301 more effective at distinguishing morphologically-similar pollen. This would result in a higher

302 ratio of singletons to doubletons (interactions detected twice) and therefore a proportionally

303 greater estimated value of interaction richness. This demonstrates that sampling method can

304 substantially affect estimation of sampling completeness of interactions in network studies.

\section{Pollen transported by moths}

306 We identified several plants using metabarcoding that were not initially identified as the

307 same species by microscopy. Because many plants have morphologically-similar pollen, we

308 conservatively chose not to identify novel moth-flower associations by microscopy unless the

309 identification was unambiguous. Among the plants initially identified only by metabarcoding

310 were species for which moths were not previously recorded in the literature as pollinators or

311 flower-visitors (Macgregor et al., 2015), highlighting that much is still unknown about

312 pollination by moths. Some of these fitted the moth-pollination 'syndrome' (Grant, 1983),

313 being white and fragrant: Sambucus nigra (Adoxaceae), Philadelphus coronarius

314 (Hydrangeaceae), Filipendula ulmaria (Rosaceae) and Ligustrum vulgare (Oleaceae; though

315 not Syringa vulgaris, not separable in this study). However, others did not and are typically

316 associated with other pollinators: for example, Polemonium caerulum (Polemoniaceae) and

317 Trifolium spp. (Fabaceae) are visited by bees (Palmer-Jones et al., 1966; Zych et al., 2013),

318 Verbena officinalis (Verbenaceae) is most likely visited by bees and butterflies (Perkins et

319 al., 1975), whilst species of Epipactis (Orchidaceae) are generalist, with previously-known

320 visitors including diurnal Lepidoptera (Jakubska-Busse \& Kadej, 2011).

321 We found pollen from plants that, in this region, are chiefly associated with domestic

322 gardens, including two species of Hydrangeaceae, species from the tribe Mentheae

323 (Lamiaceae; includes many species grown as culinary herbs, though wild species might also

324 have occurred), Buddleja davidii (Scrophulariaceae; though a railway ran adjacent to the

325 farm and $B$. davidii is widely naturalised along railways in the UK) and Verbena officinalis

326 (Verbenaceae). Individual moths may have carried pollen several hundred metres from the

327 closest gardens to the field site. This provides new evidence to support previous suggestions

328 that moths could play an important role in providing gene flow among plant populations at

329 the landscape-scale (Miyake \& Yahara, 1998; Young, 2002; Barthelmess et al., 2006), and

330 even at continental scales for species of moths that undergo long-distance migrations 
331 (Chang et al., 2018). Such gene flow could provide benefits from nocturnal pollination even

332 to plant species that are primarily diurnally-pollinated and not pollination-limited.

333 Finally, we detected several insect-pollinated crop species (only some of which require

334 pollination for crop production): specifically, soybean Glycine max and pea Pisum sativum

335 (Fabaceae), potato Solanum tuberosum (Solanaceae), and Brassica/Raphanus sp. (includes

336 oil-seed rape; Brassicaceae). Floral phenology suggests Prunus sp. (Rosaceae) was likely

337 to be cherry ( $P$. avium, $P$. cerasus or a hybrid) rather than wild $P$. spinosa. Similarly, Rubus

$338 \mathrm{sp}$. (Rosaceae) could have been wild blackberry (matching to $R$. caesius, $R$. plicatus and $R$.

339 ulmifolius) but also matched raspberry $R$. idaeus. There is currently an extreme paucity of

340 evidence in the existing global literature to support a role of moths in providing pollination

341 services by fertilizing economically-valuable crops (Klein et al., 2007; Macgregor et al.,

342 2015). Although our findings do not prove that any of the crops recorded receive significant

343 levels of nocturnal pollination by moths, they do highlight a vital and urgent need for further

344 research into the potential role of moths as pollinators of agricultural crop species.

\section{Current methodological limitations}

346 We identified limitations with both methods, relating to the accuracy and taxonomic

347 resolution of pollen identification and the non-quantitative interaction data they generated.

348 Firstly, there was little initial overlap between identifications made by each method (of 20

349 initial assignments from microscopy and 25 from metabarcoding, only 3 plant identifications

350 were shared between methods at genus- or species-level). Because we applied the methods

351 to separate samples of moths, some differences were expected between the pollen species

352 transported. In two cases (Silene and Tilia), species identified by microscopy were discarded

353 from the metabarcoding assignments by application of the 50-reads threshold. Both species

354 had very low abundance in microscopy samples (<20 pollen grains per sample), suggesting

355 precautions against cross-sample contamination with metabarcoding might mask detection

356 of low-abundance pollen. The remaining mismatches were most probably misidentifications

357 by one or other method. Using images of pollen from species identified by metabarcoding as

358 a reference for microscopy, we re-identified several pollen morphotypes, increasing

359 agreement between the methods (19 identifications matched across methods, of which 10

360 were at genus- or species-level; Table 1). Misidentifications were arguably more likely under

361 microscopy than metabarcoding, due to the conservative approach used when applying

362 BLAST and the difficulty of unambiguously identifying pollen by microscopy.

363 Secondly, several assignments made with metabarcoding were not resolved beyond family-

364 level. Although rbcL is a popular marker region for plant barcoding (Hawkins et al., 2015) 
365 and has been shown to identify over $90 \%$ of Welsh plants to at least genus-level using blastn

366 (de Vere et al., 2012), interspecific sequence diversity within $r b c L$ is nonetheless extremely

367 low within some families (e.g. Apiaceae; Liu et al., 2014). In some cases, reference

368 sequences from multiple genera did not differ across our entire fragment, leading BLAST to

369 match query sequences to species from several genera with equal confidence. Such

370 instances could not have been further resolved using our fragment, even by alternative

371 assignment methods. Sequencing a longer fragment might increase interspecific sequence

372 variation; improvements in sequencing technology may facilitate accurate sequencing of

373 such longer amplicons (Hebert et al., 2017). Using another locus than rbcL might improve

374 taxonomic resolution; loci including ITS2 and matK are also used to metabarcode pollen

375 (Bell et al., 2016b). Sequencing two or more of these loci simultaneously might also improve

376 assignment resolution (de Vere et al., 2012), though at greater cost.

377 Thirdly, some studies have weighted interactions in networks using the number of pollen

378 grains transported, as a proxy for interaction strength (e.g. Banza et al., 2015). This

379 approach is impossible with metabarcoding, as the number of pollen grains in a sample does

380 not correlate with read depth (Pornon et al., 2016), and metabarcoding cannot definitively

381 distinguish pollen from other sources of plant DNA (e.g. residual nectar on mouthparts).

382 However, an insect's pollen load also may not be a true indicator of its efficacy as a

383 pollinator (Ballantyne et al., 2015); pollinator effectiveness differs between pairwise

384 interactions through variation in floral morphology, pollinator morphology and behaviour,

385 location of pollen on the pollinator's body, and other temporal and spatial factors besides the

386 quantity of pollen transported. Instead, interaction frequency (counting occurrences of an

387 interaction, but disregarding individual interaction strength) predicts the relative strength of

388 pollination interactions well (Vázquez et al., 2005), and was successfully generated with both

389 microscopy and metabarcoding in our study.

390 Merging metabarcoding and pollination network analysis

391 Following several recent studies which have constructed diurnal plant-pollinator networks

392 using DNA metabarcoding (Bell et al., 2017; Pornon et al., 2017), we have further

393 demonstrated the potential of metabarcoding by using it to construct nocturnal pollen-

394 transport networks for the first time (Fig. 3). We provide a detailed and reproducible

395 methodology to integrate molecular advances and ecological network analysis. Our results

396 clearly demonstrate that the capacity of metabarcoding to generate pollen-transport

397 interaction data is comparable to that of previously-used methods, such as microscopy.

398 Additionally, metabarcoding may carry several practical advantages over flower-visitor

399 observations or microscopy for studies analysing pollination networks. 
400 One such advantage is that metabarcoding is reproducible across studies, pollinator guilds,

401 and ecosystems. It is freed from observer biases inherent both in morphological identification

402 of pollen, and in other means of detecting pollination interactions such as flower-visitor

403 observations, where distribution of sampling effort among flower species can affect network

404 structure (Gibson et al., 2011) and sampling often focuses on a subset of the floral

405 assemblage (e.g. Tiusanen et al., 2016). Metabarcoding can be conducted without system-

406 specific expertise in morphological pollen identification, or prior knowledge about locally-

407 present plants or likely interactions (although such information can be used, if available and

408 robust, to increase the taxonomic resolution of species identifications). Metabarcoding may

409 reveal previously unsuspected detail in networks (Pornon et al., 2017), especially those

410 involving moths or other under-studied pollinator taxa.

411 Metabarcoding may also allow more efficient processing of samples, and therefore the

412 analysis of larger numbers of samples, than microscopy (Fig. 5). Most pollination-network

413 studies have focused on evaluating a single network, or a small number of networks under

414 variant conditions (e.g. Burkle et al., 2013). Constructing multiple replicated networks across

415 a range of treatments, sites or time points, and testing for structural differences (e.g.

416 Lopezaraiza-Mikel et al., 2007), is a powerful alternative, but can be hampered by the

417 difficulty of generating enough data for multiple, well-sampled networks. For metabarcoding,

418 investment mainly scales per-plate ( $\leq 96$ samples) rather than per-sample (Derocles et al.,

419 2018), whereas for microscopy, investment of materials and especially time increases

420 linearly for every sample, although sample-processing speed might increase slightly after an

421 initial period of learning (Fig. 5). Importantly, this increased efficiency is coupled with

422 increased reproducibility, as molecular tools treat all samples identically regardless of their

423 complexity.

424 Finally, DNA metabarcoding can streamline the generation of suitable data for incorporating

425 phylogenetic information into ecological networks (Evans et al., 2016). Recent studies have

426 found significant relationships between phylogenetic and resource overlap in mutualistic and

427 antagonistic networks (Rezende et al., 2007; Elias et al., 2013; Peralta et al., 2015);

428 metabarcoding permits simultaneous generation of both interaction and relatedness data.

429 Conclusions

430 In this study, we constructed pollen-transport networks using matched samples of moths to 431 compare between two methods for detecting and identifying pollen: DNA metabarcoding and 432 traditional light microscopy. We showed that the state-of-the-art DNA metabarcoding 433 approach is capable of generating pollen-transport interaction networks that are similar to 
434 those detected using microscopy. Indeed, with metabarcoding, we detected pollen on more

435 individual moths and detected more pollen types per moth species. These differences

436 indicate that direct comparisons between networks constructed using metabarcoding and

437 those constructed using traditional methods such as microscopy should be treated with

438 appropriate caution, but a combination of both metabarcoding and traditional methods may

439 provide the most detailed information (Wirta et al., 2014). Metabarcoding additionally

440 revealed a range of previously undocumented moth-plant interactions, and provided new

441 evidence for two possible benefits of nocturnal pollination: landscape-scale provision of plant

442 gene flow, and potential provision of the pollination ecosystem service. The metabarcoding

443 approach has considerable potential for studying pollen-transport networks and species-

444 interactions more generally.

\section{Acknowledgements}

446 This work was supported by the Natural Environment Research Council and Butterfly

447 Conservation (Industrial CASE studentship awarded to C.J.M., Project Reference:

$448 \mathrm{NE} / \mathrm{K} 007394 / 1$ ) and was conducted with ethical approval from the University of Hull

449 (Approval Code U074). We thank T. Hall for her permission to sample moths at Molescroft

450 Grange Farm. We thank A. Lucas and N. de Vere for useful discussions prior to

451 commencing labwork, and J. Downs for assistance with fieldwork. E. Moss created the moth

452 image in Fig. 1.

\section{Contribution of authors}

454 The experiment was conceived by C.J.M. under supervision by D.M.E., M.J.O.P and R.F.

455 and designed by those authors with D.H.L. and J.J.N.K. Field and laboratory work was

456 conducted by C.J.M. with advice from J.J.N.K. The metaBEAT pipeline was created by C.H.

457 and metabarcoding data was processed and analysed by C.J.M., with advice from C.H. The

458 statistical analysis was conducted by C.J.M. All authors contributed to preparing the

459 manuscript and gave final approval for publication.

\section{Data Accessibility Statement}

- Raw DNA sequence reads: Sequence Read Archive, accession number SRP102977.

462

- Bioinformatic and analytical scripts: Zenodo, doi: 10.5281/zenodo.1169319.

- Processed interaction data: Dryad doi: ...(upon acceptance) 


\section{References}

465 Ballantyne, G., Baldock, K.C.R. \& Willmer, P.G. (2015) Constructing more informative plant-

466 pollinator networks: visitation and pollen deposition networks in a heathland plant

467 community. Proceedings of the Royal Society B: Biological Sciences, 282, 20151130.

468 Banza, P., Belo, A.D.F. \& Evans, D.M. (2015) The structure and robustness of nocturnal

469 Lepidopteran pollen-transfer networks in a Biodiversity Hotspot. Insect Conservation and

470 Diversity, 8, 538-546.

471 Barthelmess, E.L., Richards, C.M. \& McCauley, D.E. (2006) Relative effects of nocturnal vs

472 diurnal pollinators and distance on gene flow in small Silene alba populations. The New

473 Phytologist, 169, 689-698.

474 Beattie, A.J. (1972) A technique for the study of insect-borne pollen. The Pan-Pacific

475 Entomologist, 47, 82.

476 Bell, K.L., Burgess, K.S., Okamoto, K.C., Aranda, R. \& Brosi, B.J. (2016a) Review and future

477 prospects for DNA barcoding methods in forensic palynology. Forensic Science

478 International: Genetics, 21, 110-116.

479 Bell, K.L., Fowler, J., Burgess, K.S., Dobbs, E.K., Gruenewald, D., Lawley, B., et al. (2017)

480 Applying pollen DNA metabarcoding to the study of plant-pollinator interactions. Applications

481 in Plant Sciences, 5, 1600124.

482 Bell, K.L., Vere, N. de, Keller, A., Richardson, R.T., Gous, A., Burgess, K.S., et al. (2016b)

483 Pollen DNA barcoding: current applications and future prospects. Genome, 59, 629-640.

484 Bosch, J., González, A.M.M., Rodrigo, A. \& Navarro, D. (2009) Plant-pollinator networks:

485 adding the pollinator's perspective. Ecology Letters, 12, 409-419.

486 Burkle, L.A., Marlin, J.C. \& Knight, T.M. (2013) Plant-pollinator interactions over 120 years:

487 loss of species, co-occurrence, and function. Science, 339, 1611-1615.

488 Chang, H., Guo, J., Fu, X., Liu, Y., Wyckhuys, K.A.G., Hou, Y., et al. (2018) Molecular-

489 assisted pollen grain analysis reveals spatiotemporal origin of long-distance migrants of a

490 noctuid moth. International Journal of Molecular Sciences, 19, 567.

491 Chao, A. (1987) Estimating the population size for capture-recapture data with unequal

492 catchability. Biometrics, 43, 783-791.

493 Cristescu, M.E. (2014) From barcoding single individuals to metabarcoding biological

494 communities: towards an integrative approach to the study of global biodiversity. Trends in

495 Ecology \& Evolution, 29, 566-571. 
496 Derocles, S.A.P., Bohan, D.A., Dumbrell, A.J., Kitson, J.J.N., Massol, F., Pauvert, C., et al.

497 (2018) Biomonitoring for the 21st Century: integrating Next-Generation Sequencing into

498 Ecological Network Analysis. In Advances in Ecological Research. Academic Press.

499 Devoto, M., Bailey, S. \& Memmott, J. (2011) The "night shift": nocturnal pollen-transport

500 networks in a boreal pine forest. Ecological Entomology, 36, 25-35.

501 Dormann, C.F., Frund, J., Bluthgen, N. \& Gruber, B. (2009) Indices, graphs and null models:

502 analyzing bipartite ecological networks. The Open Ecology Journal, 2, 7-24.

503 Dunne, J.A., Williams, R.J. \& Martinez, N.D. (2002) Network structure and biodiversity loss

504 in food webs: robustness increases with connectance. Ecology Letters, 5, 558-567.

505 Elias, M., Fontaine, C. \& Veen, F.J.F. van. (2013) Evolutionary history and ecological

506 processes shape a local multilevel antagonistic network. Current Biology, 23, 1355-1359.

507 Evans, D.M., Kitson, J.J.N., Lunt, D.H., Straw, N.A. \& Pocock, M.J.O. (2016) Merging DNA

508 metabarcoding and ecological network analysis to understand and build resilient terrestrial

509 ecosystems. Functional Ecology, 30, 1904-1916.

510 Galimberti, A., De Mattia, F., Bruni, I., Scaccabarozzi, D., Sandionigi, A., Barbuto, M., et al.

511 (2014) A DNA barcoding approach to characterize pollen collected by honeybees. PLoS

512 One, 9, e109363.

513 Galliot, J.-N., Brunel, D., Bérard, A., Chauveau, A., Blanchetête, A., Lanore, L., et al. (2017)

514 Investigating a flower-insect forager network in a mountain grassland community using

515 pollen DNA barcoding. Journal of Insect Conservation, 21, 827-837.

516 Gibson, R.H., Knott, B., Eberlein, T. \& Memmott, J. (2011) Sampling method influences the 517 structure of plant-pollinator networks. Oikos, 120, 822-831.

518 Grant, V. (1983) The systematic and geographical distribution of hawkmoth flowers in the

519 temperate North American flora. Botanical Gazette, 144, 439-449.

520 Hawkins, J., Vere, N. de, Griffith, A., Ford, C.R., Allainguillaume, J., Hegarty, M.J., et al.

521 (2015) Using DNA metabarcoding to identify the floral composition of honey: a new tool for 522 investigating honey bee foraging preferences. PLoS One, 10, e0134735.

523 Hebert, P.D.N., Braukmann, T.W.A., Prosser, S.W.J., Ratnasingham, S., deWaard, J.R.,

524 Ivanova, N.V., et al. (2017) A Sequel to Sanger: amplicon sequencing that scales. bioRxiv,

525 doi: 10.1101/191619.

526 Hofreiter, M., Poinar, H.N., Spaulding, W.G., Bauer, K., Martin, P.S., Possnert, G., et al.

527 (2000) A molecular analysis of ground sloth diet through the last glaciation. Molecular

528 Ecology, 9, 1975-1984. 
529 Huson, D.H., Auch, A.F., Qi, J. \& Schuster, S.C. (2007) MEGAN analysis of metagenomic

530 data. Genome Research, 17, 377-386.

531 Jakubska-Busse, A. \& Kadej, M. (2011) The pollination of Epipactis Zinn, 1757

532 (Orchidaceae) species in Central Europe-the significance of chemical attractants, floral

533 morphology and concomitant insects. Acta Societatis Botanicorum Poloniae, 80, 49-57.

534 Kamenova, S., Bartley, T.J., Bohan, D.A., Boutain, J.R., Colautti, R.I., Domaizon, I., et al.

535 (2017) Invasions Toolkit: current methods for tracking the spread and impact of invasive

536 species. Advances in Ecological Research, 56, 85-182.

537 Kapp, R.O., Davis, O.K. \& King, J.E. (2000) Pollen and Spores. 2nd edn. American

538 Association of Stratigraphic Palynologists Foundation, Dallas, TX.

539 King, C., Ballantyne, G. \& Willmer, P.G. (2013) Why flower visitation is a poor proxy for

540 pollination: measuring single $\square$ visit pollen deposition, with implications for pollination

541 networks and conservation. Methods in Ecology and Evolution, 4, 811-818.

542 Kitson, J.J.N., Hahn, C., Sands, R.J., Straw, N.A., Evans, D.M. \& Lunt, D.H. (2018)

543 Detecting host-parasitoid interactions in an invasive Lepidopteran using nested tagging DNA

544 metabarcoding. Molecular Ecology, doi: 10.1111/mec.14518.

545 Klein, A.-M., Vaissière, B.E., Cane, J.H., Steffan-Dewenter, I., Cunningham, S.A., Kremen,

546 C., et al. (2007) Importance of pollinators in changing landscapes for world crops.

547 Proceedings of the Royal Society B: Biological Sciences, 274, 303-313.

548 Knop, E., Zoller, L., Ryser, R., Gerpe, C., Hörler, M. \& Fontaine, C. (2017) Artificial light at

549 night as a new threat to pollination. Nature, 548, 206-209.

550 Krenn, H.W. (1990) Functional morphology and movements of the proboscis of Lepidoptera

551 (Insecta). Zoomorphology, 110, 105-114.

552 Liu, J., Shi, L., Han, J., Li, G., Lu, H., Hou, J., et al. (2014) Identification of species in the

553 angiosperm family Apiaceae using DNA barcodes. Molecular Ecology Resources, 14, 12315541238.

555 Lopezaraiza-Mikel, M.E., Hayes, R.B., Whalley, M.R. \& Memmott, J. (2007) The impact of

556 an alien plant on a native plant-pollinator network: an experimental approach. Ecology

557 Letters, 10, 539-550.

558 Macgregor, C.J., Evans, D.M., Fox, R. \& Pocock, M.J.O. (2017a) The dark side of street

559 lighting: impacts on moths and evidence for the disruption of nocturnal pollen transport.

560 Global Change Biology, 23, 697-707.

561 Macgregor, C.J., Evans, D.M. \& Pocock, M.J.O. (2017b) Estimating sampling completeness 
562 of interactions in quantitative bipartite ecological networks: incorporating variation in species

563 specialisation. bioRxiv, doi: 10.1101/195917.

564 Macgregor, C.J., Pocock, M.J.O., Fox, R. \& Evans, D.M. (2015) Pollination by nocturnal

565 Lepidoptera, and the effects of light pollution: a review. Ecological Entomology, 40, 187-198.

566 Miyake, T. \& Yahara, T. (1998) Why does the flower of Lonicera japonica open at dusk?

567 Canadian Journal of Botany, 76, 1806-1811.

568 Montoya, J.M., Pimm, S.L. \& Solé, R.V. (2006) Ecological networks and their fragility.

569 Nature, 442, 259-264.

570 Moore, P.D., Collinson, M. \& Webb, J.A. (1994) Pollen Analysis. 2nd edn. Wiley-Blackwell.

571 Oksanen, J., Blanchet, F.G., Kindt, R., Legendre, P., Minchin, P.R., O’Hara, R.B., et al.

572 (2015) vegan: Community Ecology Package. R package version 2.3-5. https://CRAN.R-

573 project.org/package=vegan.

574 Ollerton, J., Winfree, R. \& Tarrant, S. (2011) How many flowering plants are pollinated by

575 animals? Oikos, 120, 321-326.

576 Palmer-Jones, T., Forster, I.W. \& Clinch, P.G. (1966) Observations on the pollination of

577 Montgomery red clover (Trifolium pratense L.). New Zealand Journal of Agricultural

578 Research, 9, 738-747.

579 Peralta, G., Frost, C.M., Didham, R.K., Varsani, A. \& Tylianakis, J.M. (2015) Phylogenetic

580 diversity and co-evolutionary signals among trophic levels change across a habitat edge.

581 Journal of Animal Ecology, 84, 364-372.

582 Perkins, W.E., Estes, J.R. \& Thorp, R.W. (1975) Pollination ecology of interspecific

583 hybridization in Verbena. Bulletin of the Torrey Botanical Club, 102, 194-198.

584 Pornon, A., Andalo, C., Burrus, M. \& Escaravage, N. (2017) DNA metabarcoding data

585 unveils invisible pollination networks. Scientific Reports, 7, 16828.

586 Pornon, A., Escaravage, N., Burrus, M., Holota, H., Khimoun, A., Mariette, J., et al. (2016)

587 Using metabarcoding to reveal and quantify plant-pollinator interactions. Scientific Reports,

$588 \quad 6,27282$.

589 Potts, S.G., Biesmeijer, J.C. \& Kremen, C. (2010) Global pollinator declines: trends, impacts

590 and drivers. Trends in Ecology \& Evolution, 25, 345-353.

591 R Core Team. (2016) R: A language and environment for statistical computing. R

592 Foundation for Statistical Computing, Vienna, Austria.

593 Rezende, E.L., Lavabre, J.E., Guimarães, P.R., Jordano, P. \& Bascompte, J. (2007) Non- 
594 random coextinctions in phylogenetically structured mutualistic networks. Nature, 448, 925-

595928.

596 Sint, D. \& Traugott, M. (2016) Food Web Designer: a flexible tool to visualize interaction

597 networks. Journal of Pest Science, 89, 1-5.

598 Tiusanen, M., Hebert, P.D.N., Schmidt, N.M. \& Roslin, T. (2016) One fly to rule them all-

599 muscid flies are the key pollinators in the Arctic. Proceedings of the Royal Society B:

600 Biological Sciences, 283.

601 Truett, G.E., Heeger, P., Mynatt, R.L., Truett, A.A., Walker, J.A. \& Warman, M.L. (2000)

602 Preparation of PCR-quality mouse genomic DNA with hot sodium hydroxide and tris

603 (HotSHOT). BioTechniques, 29, 52, 54.

604 Tylianakis, J.M., Laliberté, E., Nielsen, A. \& Bascompte, J. (2010) Conservation of species

605 interaction networks. Biological Conservation, 143, 2270-2279.

606 Vázquez, D.P., Morris, W.F. \& Jordano, P. (2005) Interaction frequency as a surrogate for

607 the total effect of animal mutualists on plants. Ecology Letters, 8, 1088-1094.

608 Vere, N. de, Jones, L.E., Gilmore, T., Moscrop, J., Lowe, A., Smith, D., et al. (2017) Using

609 DNA metabarcoding to investigate honey bee foraging reveals limited flower use despite

610 high floral availability. Scientific Reports, 7, 42838.

611 Vere, N. de, Rich, T.C.G., Ford, C.R., Trinder, S.A., Long, C., Moore, C.W., et al. (2012)

612 DNA barcoding the native flowering plants and conifers of Wales. PLoS One, 7, e37945.

613 Wirta, H.K., Hebert, P.D.N., Kaartinen, R., Prosser, S.W., Várkonyi, G. \& Roslin, T. (2014)

614 Complementary molecular information changes our perception of food web structure.

615 Proceedings of the National Academy of Sciences of the United States of America, 111,

616 1885-1890.

617 Young, H.J. (2002) Diurnal and nocturnal pollination of Silene alba (Caryophyllaceae).

618 American Journal of Botany, 89, 433-440.

619 Zych, M., Stpiczyńska, M. \& Roguz, K. (2013) Reproductive biology of the Red List species

620 Polemonium caeruleum (Polemoniaceae). Botanical Journal of the Linnean Society, 173,

621 92-107.

622

623 


\section{Tables}

625 Table 1: harmonised plant OTUs identified by metabarcoding and microscopy. In

626 column $4,{ }^{\dagger}$ indicates an assignment initially identified by metabarcoding, but failing to meet

627 the minimum read depth threshold in any sample (Table S7). In column $5,{ }^{\ddagger}$ indicates an

628 assignment that was re-identified by comparison to pollen of species identified by

629 metabarcoding.

\begin{tabular}{|c|c|c|c|c|c|}
\hline Family & $\begin{array}{l}\text { Final } \\
\text { identification }\end{array}$ & $\begin{array}{l}\text { Initial } \\
\text { assignment } \\
\text { (metabarcoding) }\end{array}$ & $\begin{array}{l}\text { No. } \\
\text { samples }\end{array}$ & $\begin{array}{l}\text { Initial } \\
\text { assignment } \\
\text { (microscopy) }\end{array}$ & $\begin{array}{l}\text { No. } \\
\text { samples }\end{array}$ \\
\hline Adoxaceae & $\begin{array}{l}\text { Sambucus } \\
\text { nigra }\end{array}$ & Sambucus nigra & 3 & Viburnum sp. ${ }^{\ddagger}$ & 3 \\
\hline Amaranthaceae & Atriplex sp. & Atriplex sp. & 1 & $\begin{array}{l}\text { Persicaria } \\
\text { maculosa } \\
\text { (Polygonaceae) }^{\ddagger}\end{array}$ & 4 \\
\hline Apiaceae & Apioideae & Apiaceae & 3 & Apiaceae & 5 \\
\hline Araliaceae & Hedera helix & Hedera helix & 1 & - & 0 \\
\hline \multirow[t]{6}{*}{ Asteraceae } & Asteraceae 1 & Asteraceae & 4 & Taraxacum sp. ${ }^{\ddagger}$ & 1 \\
\hline & Asteraceae 2 & Asteraceae & 22 & - & 0 \\
\hline & Asteraceae 3 & Asteraceae & 1 & - & 0 \\
\hline & $\begin{array}{l}\text { Anthemideae } \\
1\end{array}$ & Asteraceae & 1 & Anthemis sp. & 4 \\
\hline & $\begin{array}{l}\text { Anthemideae } \\
2\end{array}$ & Asteraceae & $0^{\dagger}$ & - & 0 \\
\hline & $\begin{array}{l}\text { Jacobaea } \\
\text { vulgaris }\end{array}$ & $\begin{array}{l}\text { Jacobaea } \\
\text { vulgaris }\end{array}$ & 6 & Cirsium sp..$^{\ddagger}$ & 5 \\
\hline Brassicaceae & $\begin{array}{l}\text { Brassica / } \\
\text { Raphanus sp. }\end{array}$ & Brassicaceae & 4 & 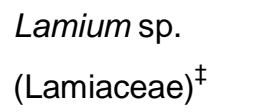 & 5 \\
\hline Caprifoliaceae & Lonicera sp. & - & 0 & Lonicera sp. & 3 \\
\hline
\end{tabular}




\begin{tabular}{|c|c|c|c|c|c|}
\hline Caryophyllaceae & Silene sp. & Silene sp. & $0^{\dagger}$ & Silene sp. & 3 \\
\hline \multirow[t]{4}{*}{ Fabaceae } & $\begin{array}{l}\text { Ulex } \\
\text { europaeus / } \\
\text { Cytisus } \\
\text { scoparius }\end{array}$ & Fabaceae & 10 & \multirow[t]{3}{*}{$\begin{array}{l}\text { Veronica sp. } \\
\text { (Plantaginaceae) } \\
\ddagger\end{array}$} & \multirow[t]{3}{*}{2} \\
\hline & Trifolium sp. & Trifolium sp. & 9 & & \\
\hline & Glycine max & Glycine max & 2 & & \\
\hline & $\begin{array}{l}\text { Pisum } \\
\text { sativum }\end{array}$ & Pisum sativum & 3 & Asparagaceae $^{\ddagger}$ & 5 \\
\hline \multirow[t]{2}{*}{ Hydrangeaceae } & $\begin{array}{l}\text { Hydrangea } \\
\text { sp. }\end{array}$ & Hydrangea sp. & $0^{\dagger}$ & - & 0 \\
\hline & $\begin{array}{l}\text { Philadelphus } \\
\text { coronarius }\end{array}$ & $\begin{array}{l}\text { Philadelphus } \\
\text { coronarius }\end{array}$ & 1 & 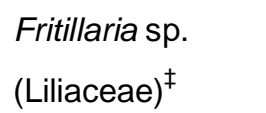 & 2 \\
\hline Lamiaceae & Mentheae & Lamiaceae & 2 & - & 0 \\
\hline Malvaceae & $\begin{array}{l}\text { Tilia } \\
\text { platyphyllos }\end{array}$ & Tilia platyphyllos & $0^{\dagger}$ & Tilia sp. & 3 \\
\hline Oleaceae & $\begin{array}{l}\text { Ligustrum } \\
\text { vulgare / } \\
\text { Syringa } \\
\text { vulgaris }\end{array}$ & Oleaceae & 23 & - & 0 \\
\hline Orchidaceae & Epipactis sp. & Epipactis sp. & 2 & - & 0 \\
\hline Papaveraceae & Papaversp. & Papaversp. & 1 & Ericaceae $^{\ddagger}$ & 1 \\
\hline Polemoniaceae & $\begin{array}{l}\text { Polemonium } \\
\text { caeruleum }\end{array}$ & $\begin{array}{l}\text { Polemonium } \\
\text { caeruleum }\end{array}$ & $0^{\dagger}$ & - & 0 \\
\hline Ranunculaceae & $\begin{array}{l}\text { Ranunculus } \\
\text { sp. }\end{array}$ & Ranunculus sp. & $0^{\dagger}$ & Helleborus sp. ${ }^{\ddagger}$ & 1 \\
\hline \multirow[t]{2}{*}{ Rosaceae } & Prunus sp. & Prunus sp. & 1 & Rosaceae & 6 \\
\hline & Rubus sp. & Rubus sp. & 26 & Rubus sp. & 13 \\
\hline
\end{tabular}


bioRxiv preprint doi: https://doi.org/10.1101/325084; this version posted May 17,2018 . The copyright holder for this preprint (which was not certified by peer review) is the author/funder, who has granted bioRxiv a license to display the preprint in perpetuity. It is made available under aCC-BY-NC-ND 4.0 International license.

\begin{tabular}{|l|l|l|l|l|l|}
\hline & $\begin{array}{l}\text { Filipendula } \\
\text { ulmaria }\end{array}$ & $\begin{array}{l}\text { Filipendula } \\
\text { ulmaria }\end{array}$ & 1 & - & 0 \\
\hline Rubiaceae & $\begin{array}{l}\text { Galium } \\
\text { aparine }\end{array}$ & Galium aparine & 1 & Galium sp. & 1 \\
\hline Scrophulariaceae & $\begin{array}{l}\text { Buddleja } \\
\text { davidii }\end{array}$ & Buddleja davidii & 19 & Buddleja sp. & 20 \\
\hline Solanaceae & $\begin{array}{l}\text { Solanum } \\
\text { tuberosum }\end{array}$ & $\begin{array}{l}\text { Solanum sp. / } \\
\text { Solanum } \\
\text { tuberosum }\end{array}$ & 7 & $\begin{array}{l}\text { Viola sp. } \\
\text { (Violaceae })^{\ddagger}\end{array}$ & 1 \\
\hline Verbenaceae & $\begin{array}{l}\text { Verbena } \\
\text { officinalis }\end{array}$ & $\begin{array}{l}\text { Verbena } \\
\text { officinalis }\end{array}$ & 1 & - & 0 \\
\hline
\end{tabular}

630

631

632 
633 Table 2: Summary of basic interaction data for each method. The samples were

634 duplicate subsets of the total sample, and each comprised 311 individuals of 41 species.

635 Plant types for metabarcoding were operational taxonomic units (OTUs; identified by a

636 BLAST search against a curated reference database) and for microscopy were morphotypes

637 (identified using identification keys). Percentages in brackets are of the relevant sub-sample.

\section{8}

\begin{tabular}{|l|c|c|}
\hline & Metabarcoding & Microscopy \\
\hline No. pollen-carrying moths & $107(34.4 \%)$ & $70(22.5 \%)$ \\
\hline No. pollen-carrying species & $15(36.6 \%)$ & $17(41.5 \%)$ \\
\hline $\begin{array}{l}\text { No. plant types identified } \\
\text { Plant types initially identified } \\
\text { to species level }\end{array}$ & $11(42.3 \%)$ & $16 \%)$ \\
\hline $\begin{array}{l}\text { Plant types initially identified } \\
\text { to at least genus level }\end{array}$ & $17(65.4 \%)$ & $5(25 \%)$ \\
\hline $\begin{array}{l}\text { Plant types detected on one } \\
\text { moth only }\end{array}$ & $10(38.5 \%)$ & $13(4.2 \%)$ \\
\hline $\begin{array}{l}\text { No. moths carrying pollen } \\
\text { from >1 plant types }\end{array}$ & $36(11.6 \%)$ & $52(88)$ \\
\hline $\begin{array}{l}\text { No. unique interactions (total } \\
\text { no. interactions) }\end{array}$ & $62(155)$ & \\
\hline
\end{tabular}

639 
bioRxiv preprint doi: https://doi.org/10.1101/325084; this version posted May 17, 2018. The copyright holder for this preprint (which was not certified by peer review) is the author/funder, who has granted bioRxiv a license to display the preprint in perpetuity. It is made available under aCC-BY-NC-ND 4.0 International license.

\section{6}

647

648

649 


\section{Figure legends}

651

652 Figure 1: visual summary of the two methods applied to detect and identify pollen

653 transport by moths. Full methods are in Appendix S1. For metabarcoding, the steps shown

654 are: 1. Field sampling of moths. 2. Excise proboscis. 3. Remove pollen by shaking. 4. Extract

655 DNA by HotSHOT method. 5. Amplify DNA by 3-step PCR protocol. 6. Sequence DNA. 7

656 Assign DNA sequence identities. 8. Analyse interactions and construct networks. For

657 microscopy, the steps shown are: A. Field sampling of moths. B. Swab proboscis with

658 fuchsin-stained gel. C. Mount gel on microscope slide. D. Identify and count pollen under

659 microscope. E. Analyse interactions and construct networks.

660

661

Figure 2: comparisons between DNA metabarcoding and microscopy approaches of:

662

proportion of (a) individual moths and (b) moth species found to be carrying pollen; number

663

of pollen types detected for (c) individual moths and (d) moth species; proportion of

664

individual moths carrying more than one pollen type (e); and estimated number of pollen

665

types per moth species (f). For (c), (d) and (f). only pollen-carrying individuals and moth

666

species were included. Significance indicates Likelihood Ratio Test for detection method in

667

GLMMs (* : $\left.P<0.05 ;{ }^{* *}: P<0.01 ;{ }^{* * *} P<0.001\right)$. Error bars show $95 \%$ confidence intervals.

668

669

Figure 3: networks constructed using DNA metabarcoding and microscopy from

670 replicated, matched samples of moths. Species are colour-coded by family (see key);

671 families appear from top to bottom in the order listed. For moths, bar height indicates relative species abundance, and link width indicates number of individuals carrying pollen of each plant species. For plants, bar height indicates number of individual moths on which each pollen type was detected, and link width indicates proportion of those moths belonging to each moth species.

676

677 Figure 4: network metrics calculated for each detection method (Table S6). Solid lines

678 connect metrics for fully-resolved data, dashed lines connect metrics when plant species 679 were aggregated at the family level. 
bioRxiv preprint doi: https://doi.org/10.1101/325084; this version posted May 17, 2018. The copyright holder for this preprint (which was not certified by peer review) is the author/funder, who has granted bioRxiv a license to display the preprint in perpetuity. It is made available under aCC-BY-NC-ND 4.0 International license.

\section{Figure 5: estimated change in investment as number of samples increases for}

682 metabarcoding and microscopy methods. Lines are hypothetical and not based on formal 683 costing of methods.

\section{4}




\section{Figures}

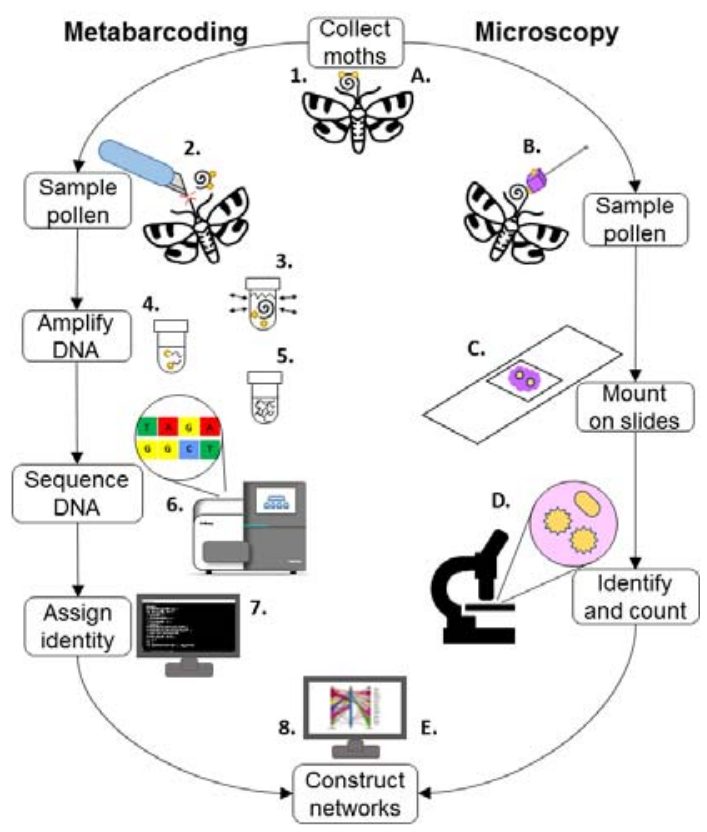

688 Figure 1: visual summary of the two methods applied to detect and identify pollen

689 transport by moths. Full methods are in Appendix S1. For metabarcoding, the steps shown

690 are: 1. Field sampling of moths. 2. Excise proboscis. 3. Remove pollen by shaking. 4. Extract

691 DNA by HotSHOT method. 5. Amplify DNA by 3-step PCR protocol. 6. Sequence DNA. 7

692 Assign DNA sequence identities. 8. Analyse interactions and construct networks. For

693 microscopy, the steps shown are: A. Field sampling of moths. B. Swab proboscis with

694 fuchsin-stained gel. C. Mount gel on microscope slide. D. Identify and count pollen under

695 microscope. E. Analyse interactions and construct networks.

696

697 

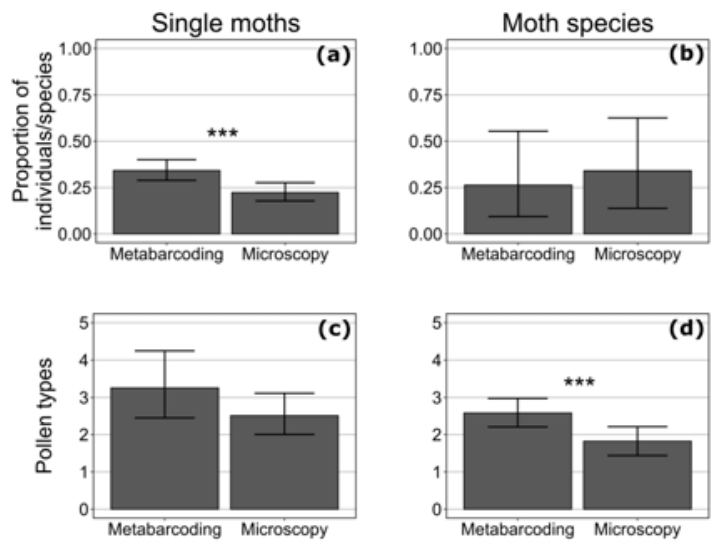

699
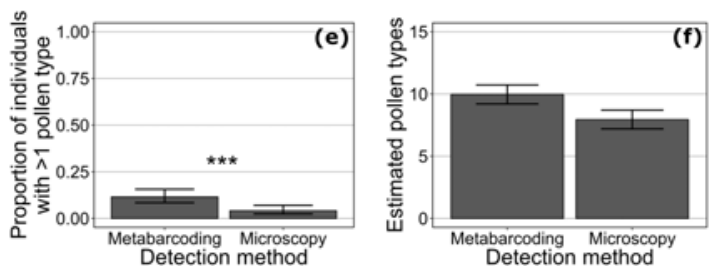

700 Figure 2: comparisons between DNA metabarcoding and microscopy approaches of:

701 proportion of (a) individual moths and (b) moth species found to be carrying pollen; number

702 of pollen types detected for (c) individual moths and (d) moth species; proportion of

703 individual moths carrying more than one pollen type (e); and estimated number of pollen

704 types per moth species (f). For (c), (d) and (f). only pollen-carrying individuals and moth

705 species were included. Significance indicates Likelihood Ratio Test for detection method in

706 GLMMs (* : $\left.P<0.05 ;{ }^{* *}: P<0.01 ;{ }^{* *} P<0.001\right)$. Error bars show $95 \%$ confidence intervals. 


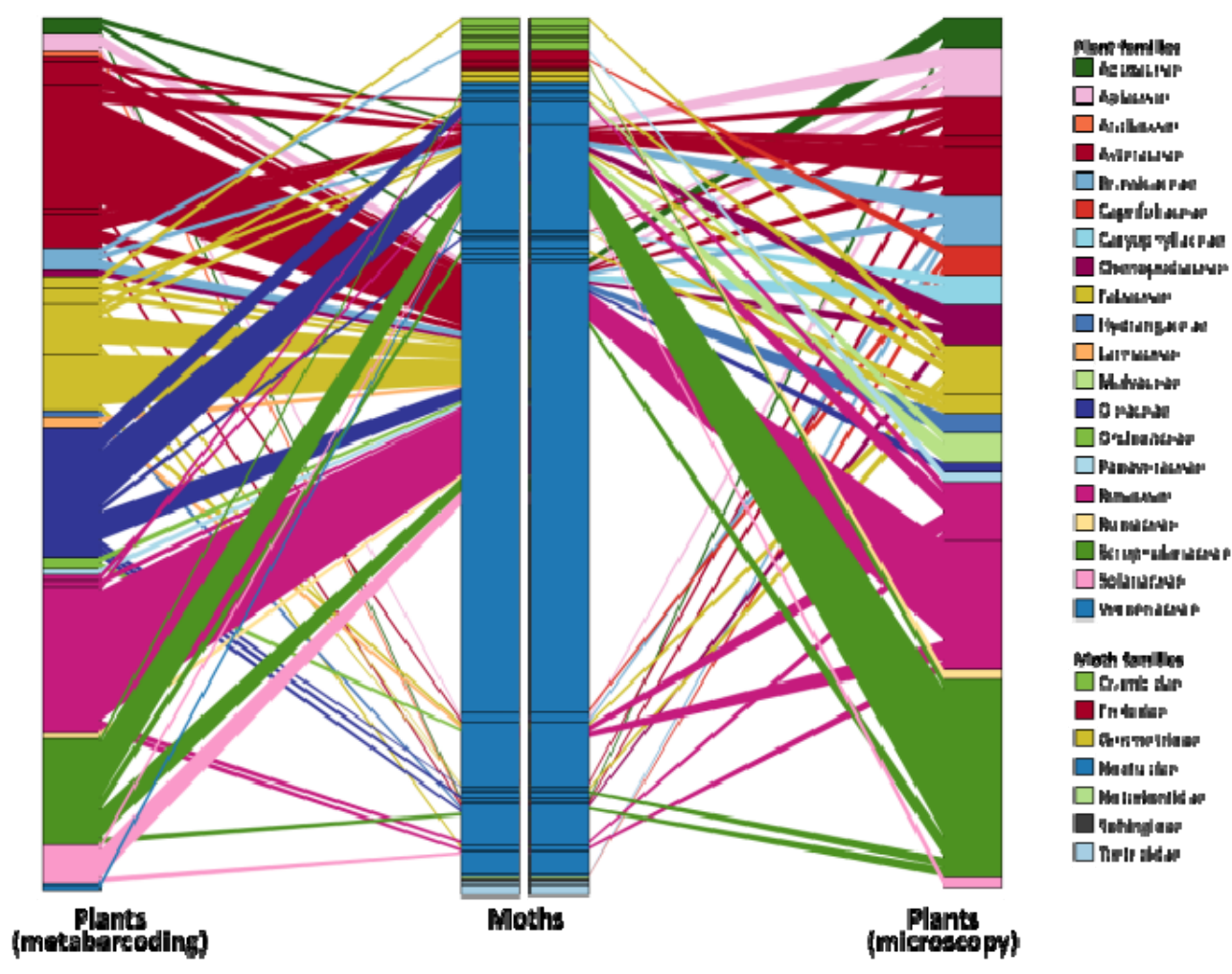

711 Figure 3: networks constructed using DNA metabarcoding and microscopy from

712 replicated, matched samples of moths. Species are colour-coded by family (see key);

713 families appear from top to bottom in the order listed. For moths, bar height indicates relative

714 species abundance, and link width indicates number of individuals carrying pollen of each

715 plant species. For plants, bar height indicates number of individual moths on which each

716 pollen type was detected, and link width indicates proportion of those moths belonging to

717 each moth species. 
bioRxiv preprint doi: https://doi.org/10.1101/325084; this version posted May 17, 2018. The copyright holder for this preprint (which was not certified by peer review) is the author/funder, who has granted bioRxiv a license to display the preprint in perpetuity. It is made available under aCC-BY-NC-ND 4.0 International license.

720
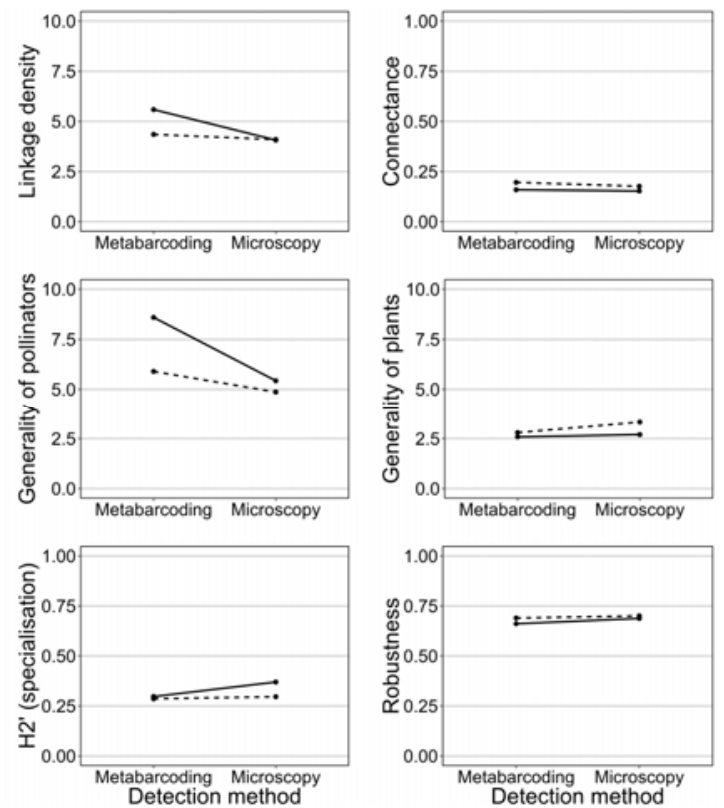

721 Figure 4: network metrics calculated for each detection method (Table S6). Solid lines

722 connect metrics for fully-resolved data, dashed lines connect metrics when plant species

723 were aggregated at the family level.

724

725 
bioRxiv preprint doi: https://doi.org/10.1101/325084; this version posted May 17, 2018. The copyright holder for this preprint (which was not certified by peer review) is the author/funder, who has granted bioRxiv a license to display the preprint in perpetuity. It is made available under aCC-BY-NC-ND 4.0 International license.

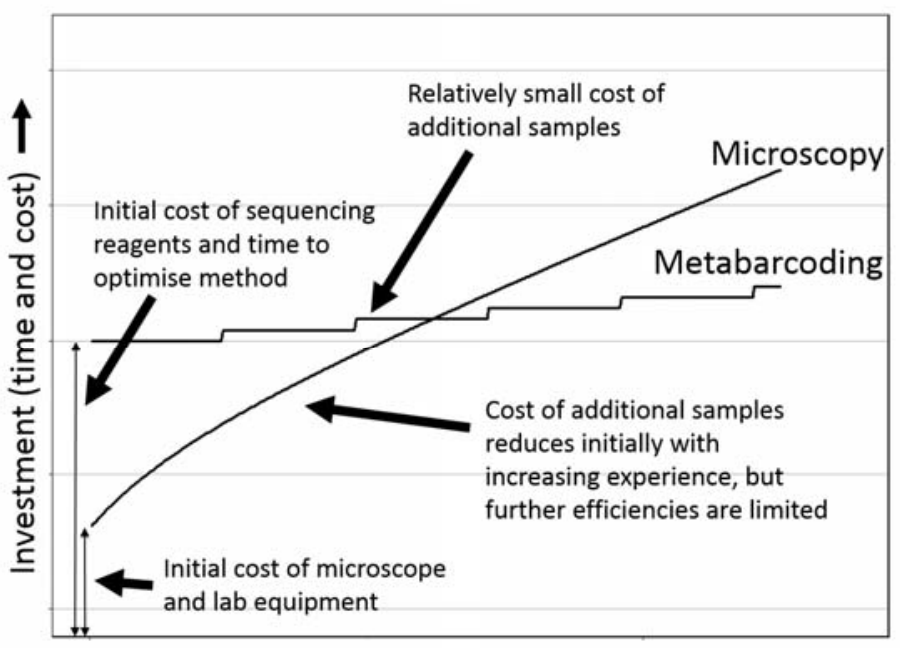

No. samples

729 Figure 5: estimated change in investment as number of samples increases for

730 metabarcoding and microscopy methods. Lines are hypothetical and not based on formal 731 costing of methods. 